\title{
ATIVIDADE ANTIBACTERIANA DE ÓLEOS ESSENCIAIS E EXTRATOS VEGETAIS SOBRE O DESENVOLVIMENTO DE Ralstonia Solanacearum EM MUDAS DE BANANEIRA ${ }^{1}$
}

\author{
EDNA PEIXOTO DA ROCHA AMORIM², FLAVIA WANESKA RODRIGUES DE ANDRADE², \\ EDLENE MARIA DA SILVA MORAES ${ }^{4}$, JULIO CESAR DA SILVA ${ }^{5}$, \\ ROSANGELA DA SILVA LIMA ${ }^{6}$, EURICO EDUARDO PINTO DE LEMOS ${ }^{7}$
}

\begin{abstract}
RESUMO - O presente trabalho teve como objetivo determinar a atividade de diferentes concentrações de óleos essenciais e extratos vegetais sobre o crescimento de Ralstonia solanacearum e a incidência do moko em mudas de bananeira. Foram avaliadas diferentes concentrações de óleos essenciais de citronela, eucalipto citriodora, cravo-da-índia e gengibre: $1,25 \% ; 3,5 \% ; 3,75 \%$ e $5 \%$ e de extratos de cravo-da-índia, gengibre, canela e melão-de-são-caetano: $5 \%, 10 \%, 15 \%$ e 20\%, medindo-se o halo de inibição da bactéria, após 48 horas. O óleo de eucalipto e os extratos de melão-de-são-caetano, cravo-da-índia e canela não apresentaram efeito sobre a bactéria. O extrato de gengibre, os óleos de citronela, de cravo e de gengibre inibiram o crescimento de $R$. solanacearumem todas as concentrações testadas, destacando-se o óleo de cravo como o melhor tratamento, seguido por extrato de gengibre. Mudas de bananeira foram pulverizadas com os óleos de citronela, gengibre e cravo (3,75\%) e extrato de gengibre (20\%), aplicando-se $10 \mathrm{ml}$ da solução por planta. Oito dias após, as mudas foram inoculadas com o patógeno $\left(10^{8} \mathrm{cel} / \mathrm{mL}\right)$. O óleo de citronela proporcionou o melhor resultado, com $100 \%$ de controle da doença, porém as folhas das plantas, com esse tratamento, apresentaram sintomas de fitotoxidez. O óleo e o extrato de gengibre foram semelhantes na eficiência de controle do moko (50\%), e o óleo de cravo apresentou menor eficiência (25\%).
\end{abstract}

Termos para indexação: controle alternativo, Musa sp., moko.

\section{ANTIBACTERIAL ACTIVITY OF ESSENTIAL OILS AND EXTRACTS ON THE DEVELOPMENT OF Ralstonia Solanacearum IN BANANA SEEDLINGS}

ABSTRACT - This study aimed to evaluate the activity of different concentrations of essential oils and plant extracts to the control of Ralstonia solanacearum. Different concentrations of the following essential oils were evaluated: citronella, Eucalyptus citriodora, clove and ginger: $1.25 \%, 3.5 \%, 3.75 \%$ and 5\%, respectively. The extracts evaluated were from clove, ginger, cinnamon and São Caetano melon: 5\%, 10\%, $15 \%$ and $20 \%$, respectively measuring the halo of inhibition of bacteria after 48 hours. The treatments with eucalyptus oil and extracts of São Caetano melon, clove and cinnamon did not differ from the control. The extract of ginger and the oils of citronella, clove and ginger inhibited the growth of $R$. solanacearum in all concentrations tested. Clove oil was the best treatment, followed by extract of ginger. Seedlings of banana were sprayed with citronella and cloves oils (3.75\%), ginger oil $(3.75 \%)$ and extract of ginger $(20 \%), 10 \mathrm{ml}$ of each solution per plant. After eight days the seedlings were inoculated with the pathogen $\left(10^{8} \mathrm{CFU} / \mathrm{mL}\right)$. The citronella oil provided the best result, with $100 \%$ control of the disease, but the leaves showed symptoms of phytotoxicity. The oil and extract of ginger were similar in effectiveness of moko control $(50 \%)$, and cloves oil showed lower efficiency (25\%).

Index terms: control alternative, R.solanacearum, Musa spp.

\footnotetext{
${ }^{1}$ Trabalho Sinfruit 032 - Simpósio Internacional de Fruticultura - Avanços na Fruticultura (17 a 21 Outubro)

${ }^{2}$ Engenheira Agrônoma - Dsc, Professora Associada, UFAL- Universidade Federal de Alagoas.- BR 104 km 76, Rio Largo-AL. edna. peixoto@pq.cnpq.br (autor correspondente)

${ }^{3}$ Engenheira Agrônoma- Mestre em Agronomia (Produção Vegetal), UFAL-AL

${ }^{4}$ Biológa, Doutoranda em Proteção de Plantas, UFAL- AL

${ }^{5}$ Engenheiro Agrônomo, Doutorando em Proteção de plantas, UNESP- Universidade Estadual Paulista, Botucatu-SP

${ }^{6}$ Zootecnista, Mestranda em Agronomia (Produção Vegetal), UFAL- AL

7Prof. UFAL-AL - Laboratório Bio Vegetal. E-mail: eepl@uol.com.br
} 


\section{INTRODUÇÃO}

A banana (Musa spp.), uma das frutas mais populares e mais consumidas no mundo, é cultivada na maioria dos países tropicais. Embora o Brasil tenha sido, em 2007, o quarto maior produtor, com 6.972.408 de toneladas, sua produtividade ainda é baixa (AGRIANUAL, 2010) devido aos sérios problemas fitossanitários que estão difundidos em todas as regiões produtoras, entre os quais a ocorrência do moko causado por Ralstonia solanacearum (Smith) (Yabuuchi et al.) (sin. Pseudomonas solanacearum Smith), reconhecida por causar perdas significativas à produção (HAYWARD, 1994).

Em bananeira, a murcha-bacteriana, causada por $R$. solanacearum raça 2, é uma doença vascular sistêmica (BUDDENHAGEN; KELMAN, 1964;COSTA et al., 2007), conhecida popularmente como moko-da- bananeira, que pode atacar todos os órgãos da planta, com danos também visíveis em plantas jovens, nas quais ocorre o amarelecimento das folhas mais novas, seguido de murcha e ressecamento que podem refletir na perda total da produção (COELHO NETTO; ASSIS, 2002).

Existe uma grande dificuldade no controle do moko, devido a uma ampla gama de hospedeiros, alta variabilidade genética e sobrevivência do patógeno no solo por longos períodos (TAKATSU et al., 1984), sendo ele baseado em práticas culturais, como eliminação de ráquis florais ou das plantas ou materiais vegetativos contaminados e ensacamento dos frutos; na aplicação de agroquímicos e na utilização de variedades resistentes, são poucos os relatos na literatura de aspectos relacionados ao controle alternativo (HAYWARD, 1994). Dentre as opções de manejo fitossanitário compatíveis com a qualidade ambiental, citam-se o uso de extratos vegetais possuidores de substâncias bioativas, capazes de atuarem como indutores de resistência às doenças em plantas (SANTOS et al., 2007), e a exploração da atividade biológica dos metabólitos secundários dos óleos essenciais de plantas surge como uma forma potencial de controle alternativo de doenças das plantas cultivadas.

O Brasil é um dos países mais ricos do mundo em espécies vegetais, devendo-se buscar nesta biodiversidade substâncias que atuem sobre doenças e pragas das culturas, visando a minimizar os efeitos negativos do uso indiscriminado de defensivos e aumentar a produção de alimentos de melhor qualidade, propiciando assim o desenvolvimento de uma agricultura alternativa e sustentável (BETTIOL, 1991).

O objetivo deste trabalho foi avaliar o controle alternativo do moko em mudas de bananeira da variedade Maçã, utilizando óleos essenciais e extratos vegetais aquosos, almejando obter uma produção com qualidade fitossanitária.

\section{MATERIAL E MÉTODOS}

Os experimentos foram conduzidos no Laboratório de Fitopatologia e casa de vegetação do Centro de Ciências Agrárias (CECA) da Universidade Federal de Alagoas (UFAL) - Câmpus Delza Gitaí, em Rio Largo.

No Experimento in vitro, foram avaliados oito tratamentos: óleos essenciais de citronela (Cymbopogon nardus), eucalipto (Eucalyptus spp.), cravo-da-índia (Caryophyllus aromaticus L.) e gengibre (Zingiber officinalis), nas concentrações de $1,25 \%, 3,5 \%, 3,75 \%$ e $5 \%$, e extratos de cravo-daíndia, gengibre, canela (Cinnamomum zuylanian) e melão-de-são-Caetano (Mormodica charanha) foram empregadas nas concentrações de 5\%,10\%, 15\% e $20 \%$, além da testemunha (bactéria + meio de cultura). O óleo de citronela foi obtido pela metodologia de arraste de vapor d'água, descrita por Stangarlin et al.(1999). O óleo de eucalipto, variedade citriodora, foi produzido por Coala Essências Aromáticas Ltda. (Fazenda São Benedito s/n, CEP 17300-00, Dois Córregos - SP. (sac@coala.com.br), os óleos de cravo e gengibre foram produzidos por Terapeuta/ Naturalista: Amorim, (amorimflora@hotmail. com). Para a obtenção dos extratos vegetais, foram pesados $5 \mathrm{~g}$ do material vegetal (folhas, caule, flores e raízes), que foi triturado em $50 \mathrm{~mL}$ de água destilada esterilizada em liquidificador, por um tempo de 10 minutos. Em seguida, o material foi filtrado em gaze dupla, papel de filtro Whatman $\mathrm{n}^{\circ} 41$ e membrana filtrante de porosidade de $0,45 \mathrm{~mm}$, sendo usado logo após sua obtenção (RIBEIRO; BEDENDO, 1999). $\mathrm{O}$ isolado $R$. solanacearum, proveniente da cidade de Coari (B-40), no Estado de Amazonas, foi cultivado em meio de BDA (batata-dextrose-ágar), sendo incubado à temperatura de $28^{\circ} \mathrm{C}$, por um período de 48 horas. Procedendo-se após esse período a preparação da suspensão bacteriana, cuja concentração foi ajustada em escala de McFarland para a concentração de $10^{8}$ células $/ \mathrm{mL}$.

A patogenicidade do isolado foi testada em frutos e em mudas de bananeira da variedade Maçã, através de picada nos frutos sadios e injeção da suspensão $\left(10^{8} \mathrm{cel} / \mathrm{mL}\right)$ em rizomas de mudas de bananeira. A bactéria foi reisolada em meio BDA, completando os postulados de Koch.

Uma suspensão aquosa $(0,1 \mathrm{~mL})$ de $R$. solanacearum $\left(10^{8} \mathrm{cel} / \mathrm{mL}\right)$ com 48 horas de cultivo 
foi espalhada, com alça de vidro, na superfície de uma placa de Petri contendo o meio BDA; posteriormente, os discos de papel de filtro $(1,6 \mathrm{~cm}$ $\varnothing)$ esterilizados em autoclave foram imersos nas diferentes concentrações dos óleos essenciais ou extratos vegetais e distribuídos equidistantes sobre a placa de Petri contendo a suspensão da bactéria. As placas foram mantidas, sem inverter, à temperatura de $35^{\circ} \mathrm{C}$, durante 48 horas, em estufa de fotoperíodo (BOD), quando foram feitas as medições dos halos de inibição.

O delineamento experimental foi o inteiramente casualizado, em arranjo fatorial ( 8 $\mathrm{x} 4+1$ ), sendo oito tipos de produtos, em quatro concentrações mais a testemunha, com quatro repetições, constituídas cada uma por 1 disco.

Mudas micropropagadas de bananeira da variedade Maçã com $20 \mathrm{~cm}$ de altura, adquiridas no laboratório de Biotecnologia Vegetal da UFAL (BIOVEG), foram pulverizadas com as concentrações de $10 \mathrm{~mL}$ de cada solução do produto por planta, que apresentaram melhor desempenho in vitro: óleos de citronela, gengibre e cravo $(3,75 \%)$, e extrato de gengibre (20\%). As testemunhas foram pulverizadas somente com água esterilizada. O delineamento experimental utilizado foi o inteiramente casualizado, com cinco tratamentos e sete repetições. $\mathrm{O}$ experimento foi reptido

Oito dias após a aplicação dos produtos testados, mudas de bananeira, cujas raízes tiveram as extremidades cortadas com tesoura esterilizada, foram inoculadas por imersão em suspensão com 10 ${ }^{8} \mathrm{cel} / \mathrm{ml}$ de $R$. solanacearum, por um período de 30 minutos.

Foi realizado o replantio das mudas nos vasos com substrato esterilizado, seguido de uma irrigação moderada, sendo mantidas em casa de vegetação, por um período de 20 dias, quando foi feita a avaliação. Para a quantificação da incidência de doença, foi utilizado o método direto, expresso em porcentagem de plantas doentes.

\section{RESULTADOS E DISCUSSÃO}

$\mathrm{O}$ isolado de $R$. solanacearum mostrou-se patogênico à bananeira cultivar Maçã, tanto em frutos como em mudas. Os frutos inoculados com a suspensão bacteriana apresentaram sintomas iniciais de escurecimento da polpa no $2^{\circ}$ dia após a inoculação, com aumento de intensidade aos 5 dias; já as mudas apresentaram sintomas leves de murcha e amarelecimento no $4^{\circ}$ dia após a inoculação, sendo observado que a intensidade da doença aumentou 10 dias após a inoculação.

\section{Inibição in vitro de Ralstonia solanacearum}

O óleo de eucalipto e os extratos de melãode-são-caetano, cravo-da-índia e canela não inibiram o crescimento da bactéria. No entanto, o extrato de gengibre, os óleos de citronela, de cravo e de gengibre foram capazes de inibir o crescimento de $R$. solanacearum em todas as concentrações testadas, com destaque para o óleo de cravo, seguido pelo extrato de gengibre.

A concentração e o tipo de óleo essencial e o extrato vegetal influenciaram na inibição do crescimento bacteriano (Figura 1). O extrato de gengibre e os óleos de citronela, cravo e gengibre proporcionaram uma significativa regressão a $5 \%$ de probabilidade, pelo teste F. Observa-se que o halo de inibição de crescimento da bactéria aumentou significativamente $(\mathrm{P}=0,05)$ com o aumento da concentração dos óleos essenciais até a concentração de $3,75 \%$, enquanto para o extrato de gengibre, o aumento do halo de inibição ocorreu proporcionalmente à concentração do produto, ou seja, à medida que se aumentou a concentração do produto, houve aumento do halo de inibição

Vários trabalhos têm mostrado que extratos e óleos inibem o crescimento de fitopatógenos in vitro, incluindo bactérias. Véras e Yuyama (2001) detectaram atividade antagônica in vitro do óleo essencial e extrato de pimenta-longa (Piper aduncum) no crescimento de $R$. solanaceraum. Também Véras et al. (2002) utilizaram óleos de paurosa (Aniba duckei) e castanha-de-cutia (Couepia edulis) e extrato etanólico de comigo-ninguém-pode (Dieffenbachia picta) para a inibição do crescimento de $R$. solanacearum, verificando que apenas o extrato de comigo-ninguém-pode foi eficiente. Já VigoSchultz et al. (2005) relataram a atividade de extratos alcoólicos de erva-cidreira, alecrim e guaco in vitro sobre o crescimento de Xanthomonas axonopodis pv. phaseoli. Oliveira et al. (2010), trabalhando com óleo e extratos vegetais e sais sobre bactérias fitopatogênicas, obtiveram a inibição do crescimento de Xcv (Xanthomonas campestris pv. vesicatoria) e Xcc (X. campestris pv. campestris) com extratos de hortelã e de $X c v, X c c$ e Pcc (Pectobaterium carotovorum subsp. carotovorum) com extratos de alho.

No entanto, a maioria dos trabalhos nessa linha de pesquisa relata o controle de fungos fitopatogênicos. Souza et al. (2004) testaram os óleos de eucalipto e citronela para inibição de Monilinia fructicola, agente causal da podridão-parda-dopessegueiro, comprovando este potencial apenas no óleo de citronela. Resultados semelhantes foram observados no presente trabalho, em que o óleo 
de citronela apresentou efeito inibidor, enquanto o óleo de eucalipto não reduziu significativamente o crescimento de $R$. solanacearum.

$\mathrm{O}$ efeito antimicrobiano in vitro do gengibre também já foi verificado para fungos fitotopatogênicos. Kane et al. (2002) observaram redução de $100 \%$ do crescimento micelial de Rhizoctonia solani, quando utilizaram o extrato de gengibre. Tylkowska e Dorna (2001) também observaram que esse extrato inibiu o crescimento micelial de Alternaria brassicae, A. brassicicola, Botrytis alii e Stemphlium botryosum. Rodrigues et al. (2007) constataram atividade antimicrobiana de extratos de gengibre sobre o crescimento micelial e produção de escleródios de Sclerotinia sclerotiorum em alface.

\section{Intensidade do Moko em bananeiras tratadas com substâncias alternativas}

Os produtos testados mostraram-se eficientes em controlar o moko em mudas de bananeira (Figura 2). O óleo de citronela proporcionou 100\% de controle da doença, porém as folhas das plantas apresentaram leves sintomas de fitotoxidez. Tanto o óleo quanto o extrato de gengibre reduziram a incidência da doença em $50 \%$, enquanto o óleo de cravo proporcionou apenas $25 \%$ de controle. Todas as testemunhas apresentaram murcha foliar e amarelecimento, assim como escurecimento dos vasos do pseudocaule, sintomas característicos do moko.

Os resultados proporcionados pelo óleo de cravo ficaram abaixo da expectativa, tendo em vista seu bom desempenho na redução do crescimento in vitro de $R$. solanacearum. Possivelmente, as substâncias antimicrobianas presentes neste óleo não estariam mais ativas ou em concentrações necessárias para maior redução da incidência da doença, quando as plantas foram inoculadas, tendo em vista que o tratamento com o referido óleo essencial ocorreu oito dias antes da inoculação do patógeno. Além disto, a forma de aplicação do produto ou a formulação escolhida podem não ter sido adequadas. Silva (2007) também não obteve resultados satisfatórios ao trabalhar com este óleo no controle do mal-dopanamá. Bowers e Locke (2000), estudando o efeito de extratos botânicos na densidade de populações de $F$. oxysporum em solo, afirmaram que houve resultados significativos quando aplicado emulsão aquosa de extratos formulados de cravo, extrato de pimenta combinado com óleo essencial de mostarda e extrato de cássia aplicado no solo, favorecendo a redução da densidade do patógeno no solo e a redução de sintomas em plântulas de melão, em casa de vegetação. Isto sugere que, por ser um patógeno habitante do solo, o controle deve ser mais fácil se realizado neste ambiente.

Embora existam na literatura vários trabalhos mostrando a eficiência de extratos in vitro, sobre diferentes fitopatógenos, poucos mostram o efeito destes sobre os fitopatógenos em plantas e não há relato do controle do moko ( $R$. solanacearum) com óleos essenciais e extratos vegetais. No caso de outros patossistemas, o controle do mal-dopanamá em casa de vegetação foi obtido pelo óleo de citronela e pelos extratos de cravo e alho e Ecolife ${ }^{\circledR}$,respectivamente, na ordem de $75 \%$, $71 \%, 75 \%$ e $91,77 \%$, respectivamente (SILVA, 2007). O gengibre induziu resistência à Bipolaris sorokiniana na variedade Embrapa 128 de cevada (SILVA;BACH 2004) e promoveu a redução da incidência de Sclerotinia sclerotiorum em plantas de alface (RODRIGUES et al., 2007).

Apesar da inexistência de trabalhos relacionados ao tratamento de plantas de bananeira com óleos essenciais e extratos vegetaispara o controle do moko, os resultados encontrados neste trabalho sugerem que o uso de óleo de citronela e gengibre e do extrato de gengibre têm potencial e podem ser uma alternativa a mais para o controle dessa doença. Após vários outros testes, esta nova tecnologia poderá ser repassada para pequenos produtores, minimizando o uso de fungicidas convencionais e, consequentemente, ajudando na preservação do meio ambiente, na proteção à saúde dos trabalhadores, assim como na melhoria do produto com relação à qualidade e longevidade. 

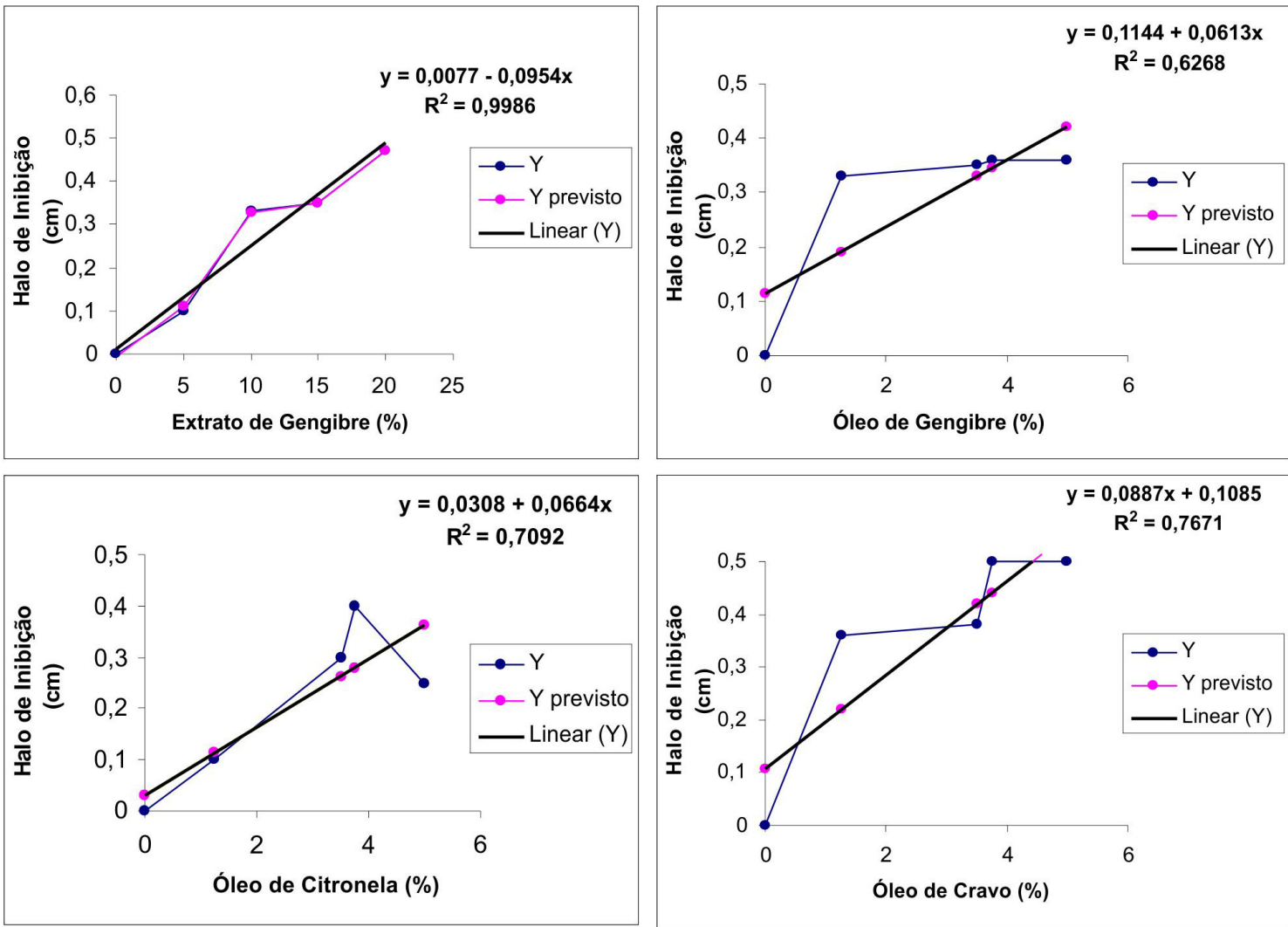

FIGURA 1 - Efeito das concentrações de óleos essenciais de gengibre, citronela e cravo e do extrato de gengibre no crescimento de Ralstonia solanacearum, pela formação de halo de inibição.

\section{Redução da incidência da doença (\%)}

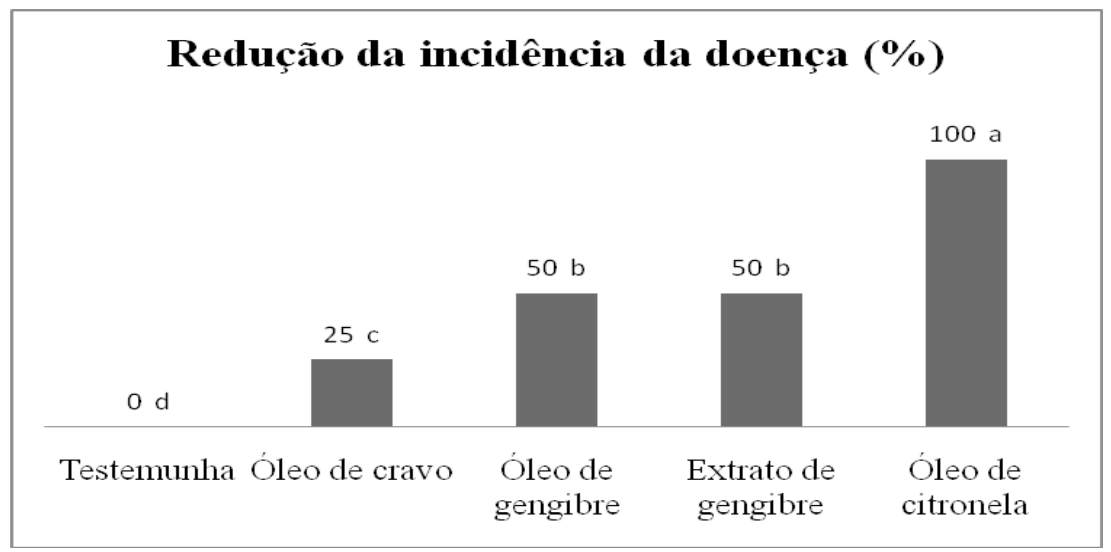

FIGURA 2 - Efeito de óleos essenciais e extrato vegetal sobre a incidência do moko de mudas de bananeira maça. Médias seguidas por letras distintas diferem significativamente entre si, pelo teste de Duncan, ao nível 5\% de probabilidade. $\mathrm{CV}=6,20 \%$. 


\section{CONCLUSÃO}

O conhecimento do efeito antimicrobiano dos óleos de citronela, gengibre e cravo e do extrato de gengibre poderá contribuir para o desenvolvimento de novas alternativas, fundamentais para o manejo do moko-da-bananeira, minimizando o aparecimento de microrganismos resistentes, bem como a contaminação do meio ambiente, tendo em vista que a incidência de moko em mudas de bananeira var. Maçã foi reduzida com o tratamento das plantas com esses produtos, com variação de 100 a $25 \%$ de controle.

\section{REFERÊNCIAS}

AGRIANUAL: Anuário da Agricultura Brasileira. São Paulo: FNP Consultoria \& Agroinformativos, 2010. p. 192-204.

BETTIOL, W. Controle biológico de doenças de plantas. Jaguariúna: EMBRAPA CNPDA, 1991. 388p. (Documentos, 15)

BOWERS, J. H.; LOCKE, J. C. Efecct of botanical extrats on the population density of Fusarium oxysporum in soil and control Fusarium wilt in the greenhouse. Plant Disease, St Paul, v.84, p.300-305, 2000 .

BUDDENHAGEN, I.; KELMAN, A. Biological and Physiological Aspects of Bacterial Wilt Caused by Pseudomonas solanacearum. Annual Review of Phytopathology, Palo Alto, v.2, p. 203-230. 1964.

COELHO NETTO, R. A.; ASSIS, L. A. G. Coleus barbatus: um novo hospedeiro de Ralstonia solanacearum. Fitopatologia Brasileira, Brasília, v.27, p. 226. 2002.

COSTA, S. B.; FERREIRA, M. A. S. V.; LOPES, C. A. Diversidade Patogênica e Molecular de Ralstonia solanacearum da Região Amazônica Brasileira. Fitopatologia Brasileira, Brasília, v.32, p.285-294. 2007.

HAYWARD, A. C. The hosts of Pseudomonas solanacearum. In: HAYWARD, A.C.; HARTMAN, G.L. (Ed.). Bacterial wilt - the disease and its causative agent, Pseudomonas solanacearum. Wallingford: CAB International, 1994. p.9-24.
KANE, P. V.; KSHISARGAR, C. R.; JADHAV, A. C.; PAWAR, N. B. In vitro evaluation of some plant extracts against Rhizoctonia solani from chickpea. Journal of Maharashtra Agricultural Universities, Mumbai, v.27, p.101-102, 2002

OLIVEIRA, W. J. et AL. Ação de óleo e extratos vegetais e sais sobre bactérias fitopatogênicas importantes em Pernambuco. In: JORNADA DE ENSINO, PESQUISA E EXTENSÃO - JEPEX, 10., 2010, Recife. Anais... UFRPE: Recife, 2010. Disponível em: <http://www.sigeventos.com.br/ jepex/inscricao/resumos/0001/R0353-1.PDF>. Acesso em: 31 maio 2011.

RODRIGUES, E.; SCHAWAN-ESTRADA, K. R. F.; FIORI-TUTIDA, A. C.; STANGARLIN, J. R.; CRUZ, M. E. S. Fungitoxicidade, atividade elicitora de fitoalexinas e proteção de alface em sistema de cultivo orgânico contra Sclerotinia sclerotiorum pelo extrato de gengibre. Summa Phytopathologica, Botucatu, v.33, p.124-128, 2007.

SANTOS, F. S.; SOUZA, P. E.; RESENDE, M. L.V.; POZZA, E. A.; MIRANDA, J. C.; RIBEIRO JÚNIOR, P. M.; MANERBA, F. C. Efeito de Extratos Vegetais no Progresso de Doenças Foliares do Cafeeiro Orgânico. Fitopatologia Brasileira, Brasília, v.32, p.59-63, 2007.

SILVA, J. C. Uso de óleos essenciais, extratos vegetais e indutores de resistência no controle alternativo do mal-do-panamá da bananeira. 2007. Dissertação (Mestrado) - Universidade Federal de Alagoas, Rio Largo, 2007.

SILVA, A. A. O.; BACH, E. E. Indução de resistência em plantas de cevada contra Bipolaris sorokiniana utilizando extrato de gengibre. Arquivos do Instituto Biológico, São Paulo, v.71, p.1-749, 2004. Suplemento

STANGARLIN, J. R.; SCHWAN-ESTRADA, K. R. F.; Cruz, M. E. S.; NOZALI, M. H. Plantas medicinais. Plantas medicinais e controle alternativo de fitopatógenos. Revista Biotecnologia Ciência \& Desenvolvimento, Brasília, v.11, p.16-21, 1999.

TAKATSU, A.; SILVA, C. B.; REIFSCHNEIDER, F. J. B. Variabilidade e distribuição de Pseudomonas solanacearum de solanáceas nas diferentes regiões do Brasil. Fitopatologia Brasileira, Brasília, v.9, p.387, 1984. 
TYLKOWSKA, K.; DORNA, H. Effects of cinnamom, garlic, greater celandine, ginger and chosen fungicides on the growther of pathogenic fungi isolated from onin, cabbage and carrot seeds. Phythopathologia Polonica, Skierniewice, v.21, p.25-34. 2001.

VÉRAS, S. M.; YUYAMA, K. Atividade Antagônica in vitro do óleo essencial e extrato de pimenta-longa (Pipper aduncum), no crescimento de Ralstonia solanacearum Raças 1 e 2. Fitopatologia Brasileira, Brasília, v.26, p.13, 2001. Suplemento
VÉRAS, S. M.; KAORU, Y.; ROCHA, S. N.; PINHEIRO, C. C. Extratos e óleos voláteis vegetais com potencial para controle de Ralstonia solanacearum. Fitopatologia Brasileira, Brasília, v.27, p. 085, 2002. Suplemento.

VIGO-SCHULTZ, S. C.; MARINGONI, A. C.; DEZORDI, C. Atividade de extratos alcoólicos de plantas medicinais in vitro sobre Xanthomonas axonopodis pv. phaseoli. Fitopatologia Brasileira, Brasília, v.30, p. 007, 2005. Suplemento. 